DOI 10.19195/2084-2546.27.11

\author{
ARTUR GARCIA FUSTER \\ ORCID: 0000-0002-9250-3590 \\ Sveučilište u Zadru \\ Correo: artur.g.fuster@gmail.com
}

\title{
L'oralitat com a origen de la narrativa de Jesús Moncada
}

\author{
Paraules clau: oralitat — ironia - memòria - Jesús Moncada — literatura \\ catalana.
}

Certament, l'inici de la novel·la més cèlebre de Jesús Moncada, Camí de sirga, no sembla que plantegi un panorama gaire falaguer. Ens situem just al punt en què comencen les demolicions de les cases d'un poble que acabarà engolit per les aigües d'un pantà. Una casa cau estrepitosament per efecte de les màquines excavadores. És un fet tràgic, una data clau. Per explicar-nosho, l'anònim cronista que ens descobrirà totes les històries que s'amaguen en els últims anys de vida del poble, ens aplega un feix de testimonis orals que exemplifiquen com es va viure la darrera nit d'aquesta vila.

Aquests testimonis són escruixidors. Diuen que el rellotge del campanar es va aturar durant la vigília. L'avaria era una clara premonició del que havia de passar l'endemà, en què també s'aturaria per sempre més el temps de vida del poble. Altres testimonis afirmen que el capvespre anterior va ser tempestuós, que la pluja, entre un cel roig i violaci, semblava que ataqués el poble. Els testimonis parlen d'un silenci espès, d'uns carrers deserts. D'uns habitants esporuguits, tancats a casa, pregant perquè no arribés mai l'endemà, la data fatídica en què, oficialment, començaria la destrucció definitiva del poble. Certament, ens diu el cronista, tots els testimonis tenien un punt en comú: eren esborronadors. També en tenien un altre, però. Tots, absolutament tots, eren també falsos.

Amb aquest irònic inici, Jesús Moncada dona el tret de sortida de la novel·la, i en marcarà clarament el to. L'autor posarà en relleu al llarg de l'obra la fragilitat de la memòria i de la transmissió oral amb una multitud de personatges $\mathrm{i}$ històries. Més, en un context tràgic com és el de la desaparició d'un poble, que deriva en uns comportaments ben singulars per part dels seus habitants. 
L'escriptor emmarca aquest torrent d'històries en una societat, sembla, molt peculiar: la mequinensana de finals del XIX i els primers dos terços, grosso modo, del segle XX. Es tracta d'un poble amb una ubicació especial, que acaba esdevenint un niu de múltiples relats. Tots aquests episodis, que s'aniran encadenant, amb analepsis i prolepsis al llarg de la novel'la, parteixen, en realitat, de la convivència entre les diverses persones que conformen el nucli humà d'aquest poble, de les relacions entre els uns i els altres, de disputes, enveges, rumors i xafarderies que s'han anat transmetent de generació en generació, amb la manipulació inherent que tot això comporta. Com bé descriu l'escriptor i crític Joan Todó:

Qui hagi viscut en un poble (o en una ciutat provinciana) sap que, durant anys, les converses poden girar al voltant d'uns pocs temes, generalment protagonitzats per un individu o una família del mateix municipi, algú que l'ha feta grossa: [...] De conversa en conversa, la narració dels fets va modificant-se, es va creant la temptativa, més aviat fràgil, d'una versió col·lectiva, no gaire fiable i sempre subjecta (segons amb qui parlis) a contradiccions ${ }^{1}$.

\section{És exactament això el que passa a la Mequinensa de Moncada.}

Ens trobem davant, doncs, d'una societat eminentment oral - com la majoria, de fet, en els temps històrics en els quals se situa la història-, en què no hi havia un accés fàcil a l'escriptura. I, com veurem, la narrativa de Jesús Moncada parteix d'aquesta llavor sempre tan escàpola, la cultura oral, per fructificar en una ferma literatura.

Són diversos els autors que han analitzat al llarg del temps el concepte d'oralitat o "cultura oral", en relació amb la literatura o "cultura escrita". Un dels pioners fou Eric Havelock, que va ser dels primers a reivindicar el paper clau de l'oralitat en qualsevol manifestació escrita posterior:

La oralidad y la cultura escrita [...] Estas palabras caracterizan a sociedades enteras que se han basado en la comunicación oral sin utilitzar la escritura. [...] se las utiliza para identificar un determinado tipo de consciencia, que se supone que es creado por la oralidad o es expresable en la oralidad. [...] Entre ellas hay una tensión creativa recíproca ${ }^{2}$.

Valen aquestes paraules, com veurem més endavant, per a l'obra de Jesús Moncada, que s'origina precisament d'aquesta "tensió creativa recíproca". Hi ha una clara autoconsciència entre els habitants del poble sobre què suposa ser de Mequinensa i quina càrrega històrica comporta. Paral·lelament als estudis de Havelock, és també molt destacable l'aportació que va fer el suís Paul Zumthor dins del camp dels estudis de la poesia oral, basant-se en la seva formació medievalista. En aquest sentit, Zumthor també va reivindicar el paper clau de l'oralitat com a font primigènia de les històries que, amb el temps, la convenció ha considerat literatura:

${ }^{1}$ J. Todó, "Les xafarderies de Yoknapatawpha", L'Avenç, 439, (Novembre, 2017), p. 65.

${ }^{2}$ E. Havelock, "La ecuación oral-escrito: una fórmula para la mentalidad moderna", dins: D.R. Olson, N. Tottance (compiladors), Cultura escrita y oralidad, Barcelona, Gedisa, 1995, p. 25. 
Resulta inútil pensar en la oralidad de forma negativa señalando sus rasgos en contraste con la escritura. Oralidad no significa analfabetismo, el cual se percibe como una carencia, despojado de los valores propios de la voz y de toda función social positiva. [...] toda oralidad nos parece más o menos una supervivencia, un resurgir de algo anterior, de un comienzo, de un origen ${ }^{3}$.

En comptes de considerar, doncs, l'oralitat intrínsecament com a pròpia de societats analfabetes, cal tenir sempre en compte que, en realitat, és l'origen i la supervivència de molt del que ha de venir després - la literatura pròpiament dita. En aquesta oralitat de transmissió popular es basen gran part de les històries que, al cap i a la fi, narra Jesús Moncada.

La feina d'aquests dos crítics ajuda, doncs, a bandejar qualsevol prevenció acadèmica de menyspreu cap a tot allò que tingui a veure amb la cultura de l'oralitat, ja que, com expliquen, sense aquest origen no hi hauria de cap manera tot el que ha vingut després. Recollint el guant d'aquests dos autors sobretot del primer) apareix la figura de Walter J. Ong. El professor americà va ser qui va explorar amb més profunditat aquesta transició entre oralitat $\mathrm{i}$ literatura. I és que, de fet, considera Ong, la idea d'oralitat és completament inseparable de la literatura, no es pot entendre l'una sense l'altra, perquè sense tot un conglomerat d'històries de transmissió oral prèvies, mai no hauria arribat a existir la literatura. Així doncs:

La condición oral básica del lenguaje es permanente [...] Todos los textos escritos tienen que estar relacionados de alguna manera, directa o indirectamente, con el mundo del sonido, el ambiente natural del lenguaje, para transmitir sus significados. En conseqüència: "La escritura nunca puede prescindir de la oralidad"4.

L'oralitat és sempre anterior a l'escriptura. D'aquesta manera, Ong es dedica més aviat a descriure les particularitats del que denomina una "cultura oral", que, pel tema que aquí tractem, podem relacionar perfectament amb la Mequinensa literària de Jesús Moncada. Tant el temps històric en què estan situades com la concepció dels personatges i de les seves vicissituds, així ho faciliten.

Vèiem, a l'inici d'aquest escrit, com la darrera nit mequinensana, abans de la construcció del pantà, $s$ 'havia transmès a partir del testimoni oral de diverses persones que donaven la seva versió de com s'havia esdevingut — versions, irònicament, totes falses, però aquest és un altre tema. Qualsevol societat basada en la transmissió oral parteix del fet que, precisament, per aquest aspecte, tenen fins a cert punt molt limitat el seu coneixement. Prossegueix Ong, en el seu minuciós estudi: "En una cultura oral, la restricción de las

\footnotetext{
${ }^{3}$ P. Zumthor, Introducción a la poesía oral, Taurus Humanidades, 1991, p. 27.

${ }^{4}$ W.J. Ong, Oralidad y escritura: tecnologías de la palabra, México, Fondo de Cultura Económica, 1987, p. 17.
} 
palabras al sonido determina no sólo los modos de expresión sino también los procesos de pensamiento. Uno sabe lo que puede recordar" 5 .

$\mathrm{Si}$ ens situem en aquests paràmetres, cal tenir en compte que una cultura com la mequinensana, basada en l'oralitat, no disposa de gaires textos. No hi ha espais escrits on aferrar la volatilitat dels records. Per tal que tot aquest coneixement, tota aquesta tradició, prosperi d'alguna manera és imprescindible la comunicació constant entre els seus habitants. La repetició d'una història moltes vegades és el que l'acaba convertint en llegenda, i d'això, com sabem i comprovarem al llarg d'aquestes pàgines, a Mequinensa, en saben molt. No es tracta pas de llegendes en un sentit més tòpicament històric, sinó podríem dir-ne d'aires més quotidians. La diferència, per tant, entre la concepció que proposa el teòric americà i les novel·les i contes que escriu el mequinensà es basa en la transcendència que cerquen l'un i l'altre. Mentre que Ong es refereix a aquelles històries i llegendes que vertebren, amb el pas del temps, l'autopercepció d'una societat concreta (la poesia oral, el cant de gesta) ${ }^{6}$, l'obra de Moncada es basa, precisament, en la reconstrucció o reactualització irònica d'aquests relats. Relats que, com veurem, parteixen més aviat del drama familiar, la xafarderia, el rumor, l'anècdota o la broma que no pas d'esdeveniments netament històrics o memorables.

Moncada manipula, transforma i fixa aquesta memòria oral del poble de Mequinensa i la converteix en literatura. Ara bé, concretem-ho una mica. Quan parlem de memòria oral, de què estem parlant exactament? Què és el que es transmet de pares a fills? Diu un personatge mequinensà que, quan naixem, el nostre ADN pot incloure, evidentment, trets físics com el nas o les orelles del pare; però, per sort o per desgràcia, també les seves idees polítiques i l'herència de velles disputes familiars o veïnals. Odis i fílies també s'hereten de generació en generació. El traspàs del testimoni és continu, com una cursa de relleus al llarg del temps. D'aquests petits o grans drames particulars, el mequinensà en fa retaules de vida. Com comentava Sandrine Ribes en una aproximació a l'oralitat dins l'obra de Moncada: "The popular voice takes on many oral activities with varying forms: rumours and superstitions, legends and histories, etc."7.

Aquests "rumors, supersticions, llegendes i històries" són els que el filòleg Josep Murgades en un article panoràmic sobre la narrativa de Moncada ${ }^{8}$ va assimilar a un concepte ben interessant que encunyà el lingüista i crític literari André Jolles, el de "Formes simples" (en l'alemany original, Einfache Formen). Jolles definia així aquestes "formes simples":

${ }^{5}$ Ibidem, p. 40.

${ }^{6}$ Ibidem, p. 41.

7 S. Ribes, "The short stories: The Universe and Voices of Mequinensa", dins: K. Crameri (ed.), Where the rivers meet: Jesús Moncada, Nottingham. Five Leave Publications in associaton with the Anglo-Catalan Society, 2011, p. 81.

${ }^{8}$ J. Murgades, "Narrativització de formes simples: l'obra de Jesús Moncada", dins: Professor Joaquim Molas: Memòria, Escriptura, Història, vol. II, Barcelona, Publicacions de la Universitat de Barcelona, 2003, p. 759-780. 
Toutes les fois qu'une activité de l'esprit amène la multiplicité et la diversité de l'être et des événements à se cristalliser pour prendre une certaine figure, toutes les fois que cette diversité saisie par la langue dans ses elements premiers et indivisibles, et devenue production du langage peut à la fois vouloir dire et signifier l'être et l'événement, nous dirons qu'il y a naissance d'une Forme simple?.

Jolles, al llarg del llibre, analitza la dicotomia que s'ha format durant molt de temps entre el que ell anomena "formes savantes" (les formes erudites, podríem dir-ne) i aquestes "formes simples", que formen part del llenguatge humà de manera intrínseca $\mathrm{i}$ que, tradicionalment, no sempre han entrat dins del cànon més estès d'allò que es considera pròpiament "literatura". Formes de tradició orals que han anat apareixent i transformant-se al llarg dels segles fins a arribar als nostres dies.

Tot i que aquesta anàlisi es fa a partir d'exemples clàssics de la literatura europea (en gran part, dels germans Grimm) algunes de les consideracions sobre el "conte" ens poden resultar útils en aquest treball. Una n'és la de la universalitat dels contes, la creació d'una lògica interna aplicada a cadascuna d'aquestes formes: "[...] les lois de formation du conte sont telles que, toutes les fois qu'on les transporte dans l'univers, celui-ci se transforme selon un principe qui ne règne que dans cette forme et n'est déterminant que pour elle" 10 .

Aquesta idea, és clar, té molt de sentit en un autor com Moncada, creador de tot un univers propi (que engloba reculls de contes i també novel·les), regit per unes lleis i uns comportaments singulars que donen sentit a aquest món mequinensà. L'inici de Calaveres atònites és autènticament revelador en aquest sentit: "Si acceptava a ulls clucs que l'antiga Mequinensa era pel cap baix el rovell de l'ou de la galàxia, el foraster intel-ligent s'hi trobava de seguida com a casa"11. El mequinensacentrisme —podríem dir-ne- és una de les actituds bàsiques dels personatges que poblen aquestes històries i és, alhora i pel que comporta, una de les grans virtuts humorístiques.

Formes simples es tracta, en termes generals, d'una lectura interessant, reveladora i, per tant, recomanable; i, com veiem, aplicable a l'autor que aquí analitzem. Ara bé, el que més ens interessa en aquest cas és la lògica actualització del concepte de "forma simple" que podem aplicar a l'autor de la Franja. I és que les històries que planteja Jesús Moncada parteixen, sobretot, de les xafarderies, dels rumors, de les enveges o de problemes eminentment domèstics i quotidians. Són el que podríem qualificar com a "formes simples modernes". La resolució d'aquests petits conflictes o equívocs (sovint magnificats pel tremendisme dels mateixos personatges) és la trama principal sobretot, pel que fa als contes, però també d'alguns fragments de les novel·les. La vida en un poble podia ésser anodina, però aquest fet canvia completament quan passa

\footnotetext{
${ }^{9}$ A. Jolles, Formes simples, Paris, Éditions du Seuil, 1972, p. 42.

${ }^{10}$ Ibidem, p. 185.

11 J. Moncada, Calaveres atònites, La Magrana, 1999, p. 9.
} 
pel sedàs de la ploma afilada de Moncada. El gran mèrit de l'autor, a més, està en el fet que les condicions i les actituds dels personatges mequinensans acaben esdevenint un autèntic fris de la condició humana.

L'actualització d'aquest concepte de forma simple s'encara de dues maneres diferents depenent, sobretot, del punt de vista adoptat pel narrador. Això vol dir que l'oralitat té un pes diferent si estem parlant de contes o de novel·les, perquè els narradors d'uns i altres són diferents. Cal fixar-nos, per tant, en les divergències i en els punts en comú —que també n'hi ha.

Preponderantment, en els contes, va guanyant importància la forma monologada, de manera que l'oralitat la trobem en la mateixa manera d'expressarse dels personatges, que prenen directament la paraula per parlar dels seus problemes o neguits. En canvi, les novel $\cdot$ les, mantenen sempre una veu narradora "extra-diegètica"12, que se situa sempre per sobre dels ens de ficció, en un pla eminentment irònic, com vèiem a l'inici d'aquest capítol.

Això, per tant, també comportarà un tractament de l'oralitat diferent, més o menys directe pel que fa a la nostra lectura. En els contes, pel seu aspecte formal, la transmissió oral serà més clara que a les novel·les. La transmissió de les xafarderies i dels rumors és necessàriament més creïble quan es fa des del discurs directe. És el que trobem, sobretot, en els relats breus. A través de la veu directa dels personatges, del que diuen - $\mathrm{i}$, de vegades, del que calleni de com ho diuen, descobrim un munt de petites històries que, en conjunt, formen la personalitat literària del poble de Mequinensa. A les novel·les, en canvi, el narrador extern s'encarregarà, sovint irònicament, de mostrar-nos la fragilitat d'aquesta transmissió.

Sobre la concepció d'aquesta oralitat dins del poble, combinada amb la xafarderia, podem veure'n un parell d'exemples clarificadors. Pel que fa a les novel·les, ja hem observat a l'inici el to irònic amb el qual s'encara el valor del feix de testimonis que volen donar la seva versió de l'última nit del poble antic de Mequinensa l'any 1971. Una mica més endavant, també a Camí de sirga, hi trobem un dels moments estrella de la novel-la amb els berenars al Saló de les Verges Màrtirs del casal dels Torres i Camps. Allà s'hi reuneixen les amigues de Carlota de Torres per comentar i analitzar les últimes novetats que s'han produit a la vila. Evidentment, volen els punyals i, sovint, en direcció subtil a la mateixa amfitriona de la trobada. En aquest cas, la vella Estefania d'Albera, decideix treure el tema de la visita al poble del vell amant secret de Carlota de Torres, Francesc Romaguera:

Es decidí encetar el tema la senyoreta Estefania d'Albera [...].

-Diuen...

—Què? — va exclamar la Nàsia Palau, amoixada i guenya.

—Què? — va esquellejar la Teresa Solanes, abundosa i tova.

—Què? — deixà anar la Isadora Rubió, esblanqueïda i fada.

${ }^{12}$ G. Genette, Figures III, Paris, Éditions du Seuil (collection Poétique), 1972, p. 284. 
- Ja que ho voleu saber — prosseguí la senyoreta Estefania en acabar-se l'anís i guaitant de reüll la Carlota de Torres - , diuen que el Francesc Romaguera va arribar anit a la vila.

- Oh! —es va esbalair la Isadora Rubió.

—Oh! —es meravellà la Teresa Solanes.

—Oh! — va admirar-se la Nàsia Palau.

"Bandarra — va pensar la Carmela [...]. Tant de bo se t'emporti una riada!" La senyora Carlota de Torres no badà boca i encara que l'Estefania d'Albera, davant el silenci sorrut de l'amfitriona, va comprendre que havia fet sang, no s'arriscà a burxar més fondo $[\ldots]^{13}$.

Transcrivim aquest fragment de la novel-la llargament perquè és important, simbòlicament, pel que comporta a continuació. La revelació de la senyoreta Estefania d'Albera portarà al passat, curiosament, no pas el personatge afectat per la revelació, Carlota de Torres, sinó la seva minyona de confiança, la Carmela, que ha viscut tota la vida a la seva vora i li coneix els plecs de la memòria millor que ningú. Carlota de Torres, és clar, entra en còlera tan bon punt es queda sola a casa (minyones a banda) i ja no li cal dissimular més l'enuig.

A partir d'aquest instant, retrocedim en el temps per conèixer alguns dels secrets de la desigual relació entre Francesc Romaguera i Carlota de Torres: les furtives trobades sexuals i el desig que Carlota sempre ha tingut per ser alguna cosa més que una amant passatgera d'en Francesc. Així, la conversa de les quatre xafarderes - les paraules que s'hi han sentit- ha comportat un salt en el temps per narrar el passat d'un dels personatges en què l'oralitat ha estat fonamental per entendre el desenvolupament del present de la història.

No passa ben bé el mateix si ens traslladem als contes. Un bon exemple el trobarem en el relat que obre El Cafè de la Granota, "Un barril de sabó moll". Allà, el personatge del vell Cristòfol explicarà de forma ben didàctica una curiosa anècdota a partir del trasllat de la mercaderia d'un llaüt. Ens interessa ara, però, fixar-nos no tant en el contingut de la trama en si, sinó en les esparses notes de xafarderia amb les quals el narrador amaneix la història i que són, consegüentment, mostres de l'oralitat que aquí analitzem. El vell Cristòfol, de fet, no participa directament en la història i ni tan sols n'és un testimoni directe, ja que per aquestes dades remet en tot moment als records d'altres habitants, sempre fiables.

La Marieta Peris, més coneguda per la Gramola, [...] ho plegà tot fil per randa i més tard em jurà que el peó no havia badat boca; i si ella ho digué, pots escriure sense cap mania que el Florenci no la badà ${ }^{14}$.

El sobrenom d'aquest personatge ja és prou clarificador. A continuació, de manera intercalada amb la història que se'ns explica — la d'un pobre llaüter que havia de carregar un barril de sabó moll pel carrer més costerut

13 J. Moncada, Camí de sirga, La Magrana, 2001, p. 109.
14 J. Moncada, El Cafè de la Granota, Ed. 62, 2004, p. 9. 
del poble-, anirem resseguint com ho van viure altres testimonis oculars. L'Adelaida havia de ser la destinatària del barril:

La botiga de l'Adelaida era on encara és, a la punta de dalt del carreró de Sant Francesc; qui no hi és, és l'Adelaida: fugí amb un recaptador de la contribució i amb les contribucions recaptades quan tu eres encara una melitxa ${ }^{15}$.

En Miquel la "Clenxa" és el simpàtic barber del poble, que tindrà també diverses aparicions al llarg de tot aquest llibre:

Tu, a la Clenxa ja no el vas conèixer; al cap de poc d'aquesta història es va escapar amb la dona d'un manescal que vam tenir a la vila i va obrir una perruqueria al París de la França ${ }^{16}$.

Finalment, en Teodor, un apotecari, figura que sempre està preparat per valorar els fets amb apunts irònicament erudits:

Un apotecari, el Teodor, el qual tampoc vas arribar a conèixer perquè va fugir fa molts anys amb la dona d'un gallinaire que venia a vendre aviram a la plaça, va arribar a l'extrem de comparar el Florenci amb un que li deien Sísif, $[\ldots]$ ¿Caldrà que et digui que el Florenci va ser per sempre més el Sísif de la Ribera? ${ }^{17}$

Òbviament, els fragments citats no són gens casuals, i és que la repetició de la conducta fugitiva d'alguns dels testimonis dels fets no sols aporta la vessant humorística de la història, sinó que també és el model del tipus de relat oral que s'exemplifica amb aquest text, en el qual s'intercalen les típiques xafarderies de poble, que formen part de l'imaginari col·lectiu, en l'explicació dels fets. Fa més sentit que mai, doncs, la definició de xafarderia que dona Lluís Flaquer al seu assaig De la vida privada: "com aquell mitjà informal de control de la societat consistent en la intrusió (verbal) en les vides privades dels altres per tal que es conformin a les normes socials en vigor"18, ja que aquesta activitat forma part de manera indestriable de la vida dels pobles i, en conseqüència, també dels mequinensans. D'aquesta manera es comença a formar una imatge de Mequinensa feta a partir d'anècdotes i de xafarderies, sempre simpàtiques i amb un punt de trapelleria, que són les que acaben donant aquest contingut amable que ens queda del poble.

Aquest testimoni que dona el vell Cristòfol es fa des d'un espai que acabarà sent emblemàtic al llarg de tota la producció moncadiana: el cafè, un lloc clau en la concepció de les històries - tant de contes com de novel·les- perquè és l'espai des del qual són relatades en moltíssimes ocasions. Els cafès de Mequinensa són un punt de trobada fonamental per als personatges, que hi practiquen no només l'evocació de records del passat, sinó també un gène-

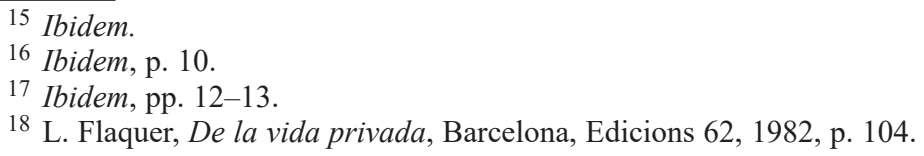

${ }^{18}$ L. Flaquer, De la vida privada, Barcelona, Edicions 62, 1982, p. 104. 
re de conversa que esdevindrà paradigmàtic del tipus de vida a Mequinensa: la tertúlia. El mateix Moncada reconeixia la influència real de les tertúlies mequinensanes ${ }^{19} \mathrm{com}$ a font de les seves històries. Un testimoni oral que, podrem comprovar-ho, trasllada perfectament a la seva literatura. Les primeres valoracions de l'obra de Moncada ja destacaven aquest fet, com, per exemple, la de l'escriptor Ignasi Riera:

Moncada juga, a més a més, amb els mecanismes del racconto popular, de cafè. Està convençut que el cafè és la Universitat més activa per la majoria, el lloc on creixen i s'ensorren fames i prestigis, l'aula oberta a tota mena de debats. [...] s'ha destacat com un autor que creu en els valors de la tradició oral, estructura bàsica sobre la qual sustenta les seves narracions ${ }^{20}$.

Aquesta estructura bàsica sobre la qual sustenta les narracions és ni més ni menys que aquesta tertúlia de la qual parlàvem. En un suggeridor assaig sobre el tema, Enrique Tierno Galván afirmava que la tertúlia era el "sustitutivo sedentario de la aventura" 21 . Efectivament, els personatges de Moncada converteixen les seves estones d'oci al poble en un autèntic intercanvi d'opinions, teories i conspiracions banals que es produeixen pel simple gaudi de fer-les. Els presumptes secrets familiars són una font d'històries inesgotable. Com diu un personatge de Calaveres atònites en el relat "Fet d'armes" a propòsit de la popularitat que ha assolit el seu petit drama familiar: "I comprenc l'interès de la gent, aquestes històries fan greix, ajuden a viure. [...] ¿Què puc fer-hi? Si jo mateix xalo amb les històries dels altres, he d'acceptar que els altres xalin amb les meves $[\ldots]^{\prime 22}$.

És, pràcticament, un quid pro quo a costa de la vida de tots plegats. Afirma també Tierno Galván que la tertúlia és purament opinió, amb un acord tàcit entre tots els contertulians: "cada uno tolera y en principio admite lo que dicen los demás, siempre que los demás toleren y en principio admitan lo que dice él" ${ }^{23}$. En el fragor de la dialèctica, no importa tant la realitat o la mentida del que es proclama perquè, al cap i a la fi, tot acaba estant subjecte a l'opinió subjectiva dels participants Com acaba passant en les novel·les i els contes de Moncada: "La tertulia se convierte en centro del chisme y de la murmuración más torpe" 24 . Només des d'aquesta òptica podem entendre les puerils disputes entre les senyores del Saló de la Verges Màrtirs i els àcids comentaris que es fan al Cafè del Moll durant diverses escenes de Camí de sirga, per exemple.

19 "Era l'àgora! Era l'antiga àgora grega; s'hi discutia de tot, del diví i de l'humà; no s'escapava res... I al costat de l'humor, que dilueix i endolceix les coses, també hi havia la mala bava que la brama sempre comporta. Les tertúlies als cafès de Mequinensa eren una meravella!"; X. Moret, Retrats: Jesús Moncada, Barcelona, AELC, 2005, p. 12.

${ }^{20}$ I. Riera, "Jesús Moncada, l'art d'un escriptor de cafè", Diari de Barcelona, 14.02.1989, p. 8.

${ }^{21}$ E. Tierno Galván, "Notas sobre la tertulia", dins: Desde el espectáculo a la trivialización, Madrid, Taurus, 1961, p. 249.

22 J. Moncada, Calaveres atònites, La Magrana, 1999, p. 98.

${ }^{23}$ E. Tierno Galván, op. cit., p. 248.

${ }^{24}$ Ibidem, p. 256. 
Les tertúlies esdevenen petits reductes de llibertat en què cada personatge es permet de dir-hi la seva. Són vies d'escapament. Segons Tierno Galván, i ho podem aplicar precisament a aquestes pàgines de Moncada: "la tertulia, particularmente en las épocas del absolutismo, ha servido [...] lo mismo que en otro aspecto la tragedia de los griegos, de catharsis social" 25 . El fet que, a la Mequinensa de Moncada, situada sovint sota el jou franquista, l'assistència a una tertúlia o una altra estigui condicionada per l'estament social, laboral o les preferències polítiques, permet a l'autor d'anar jugant amb la llibertat d'opinió que, dins d'aquests contextos privats, els personatges poden expressar. Com conclou Tierno Galván: "[...] la tertulia significa el escape, por la vía del esteticismo, de la asfixiante realidad política y social" 26 .

Les tertúlies mequinensanes són aquesta via d'escapament, l'àgora que tot ho posa en dubte, que iguala rics i pobres per la via de l'humor i del sarcasme. La font d'històries que no només les engega, sinó que és capaç d'aturarles, quan cal, per analitzar-ne i disseccionar-ne virtuts i defectes. La tertúlia de cafè és el punt d'arrencada d'aquest viatge sedentari per la vida privada dels mequinensans.

El fet que els protagonistes prenguin la paraula també ens ajudarà a conèixer una forma d'expressió peculiar que, sovint, portarà associada un aprofundiment en la psicologia del personatge, sobretot en els casos dels monòlegs. Això passarà sobretot en els contes, però també en alguns fragments de les novel·les, com els monòlegs que ens regalaran els personatges d'Arquimedes Quintana (Camí de sirga), de Cebrià de Ribesmortes (La galeria de les estàtues) o de Baltasar Garrigues (Estremida memòria). A través dels seus discursos els coneixerem més a fons. Consegüentment, cal tenir clar que els personatges de Moncada es caracteritzen també per la seva enorme capacitat explicativa i desimboltura. La naturalitat amb la qual s'expressen els personatges deu molt a l'ús de la fraseologia —un altre aspecte interessant de l'obra de Moncada, relacionat amb l'oralitat, però que no podem analitzar amb el detall necessari en aquest article.

Hem pogut comprovar quines són les coordenades orals sobre les quals Moncada traça les bases de la seva narrativa. Fixant-nos en les teories de Havelock, Zumthor i Ong hem vist com s'organitza una cultura oral primària, i com aquesta idea es pot aplicar a aquesta Mequinensa literaturitzada; sobretot en el sentit d'identificar les fonts primigènies de les quals beu aquest autor. A continuació, hem fet un primer pas per acostar els conceptes de memòria $i$ oralitat, per tal de lligar-ho amb les teories d'André Jolles i la reactulització del seu concepte de "Formes simples". Com el substrat oral d'històries diverses, més aviat quotidianes $i$ àdhuc banals, poden convertir-se en literatura. Hem comprovat com el punt de vista, sigui bé des de la novel·la o bé des del relat breu, influeix en la visió que tenim com a lectors d'aquesta oralitat, tant

\footnotetext{
${ }^{25}$ Ibidem, p. 253.

${ }^{26}$ Ibidem, p. 265.
} 
llegida pel sedàs d'un narrador extern, en el cas de les novel·les, com per la pròpia veu en el cas dels relats breus.

Aquest últim fet ens ha portat a l'anàlisi del concepte de tertúlia com a fonament de moltes de les històries, tant pel que significa com a punt d'arrencada com de comentari d'altres relats paral·lels. El punt de partida bàsic per remarcar definitivament la importància de l'oralitat dins de l'obra de Jesús Moncada.

\section{Referències bibliogràtiques}

\section{FLAQUER Lluís}

1982 De la vida privada, Barcelona, Edicions 62.

GENETTE Gérard

1972 Figures III, Paris, Éditions du Seuil (collection Poétique).

HAVELOCK Eric

1995 "La ecuación oral-escrito: una fórmula para la mentalidad moderna", dins: Olson D.R., Tottance N. (compiladors), Cultura escrita y oralidad, Barcelona, Gedisa, pp. 25-45.

JOLLES André

1972 Formes simples, trad. Antoine Marie Buguet, Paris, Éditions du Seuil.

MORET Xavier

2005 Retrats: Jesús Moncada, Barcelona, AELC.

MONCADA Jesús

2004 El Cafè de la Granota, Barcelona, Edicions 62.

2004 Estremida memòria, Barcelona, Edicions 62.

2004 Històries de la mà esquerra, Barcelona, Edicions 62.

2003 La galeria de les estàtues, Barcelona, La Magrana Butxaca.

2001 Calaveres atònites, Barcelona, La Magrana.

2001 Camí de sirga, Barcelona, La Magrana Butxaca.

MURGADES Josep

2003 "Narrativització de formes simples: l'obra de Jesús Moncada", dins: Professor Joaquim Molas: Memòria, Escriptura, Història, vol. II, Barcelona, Publicacions de la Universitat de Barcelona.

ONG Walter J.

1987 Oralidad y escritura: tecnologías de la palabra, trad. Angélica Scherp, México, Fondo de Cultura Económica.

\section{RIBES Sandrine}

2011 "The short stories: The Universe and Voices of Mequinensa", dins: Crameri K. (ed.), Where the rivers meet: Jesús Moncada, Nottingham, Five Leave Publications in associaton with the Anglo-Catalan Society, p. 56-93.

RIERA Ignasi

1989 “Jesús Moncada, l'art d'un escriptor de cafè”, Diari de Barcelona, 14.02.1989, p. 8.

TIERNO GALVÁN Enrique

1961 "Notas sobre la tertulia", dins: Desde el espectáculo a la trivialización, Madrid, Taurus. TODÓ Joan

2017 "Les xafarderies de Yoknapatawpha”, L’Avenç, 439 (Novembre, 2017), p. 65. ZUMTHOR Paul

1991 Introducción a la poesía oral, trad. M $\mathrm{M}^{\mathrm{a}}$ Concepción García-Lomas, Madrid, Taurus Humanidades. 


\section{Orality as the origin of the narrative of Jesús Moncada}

Keywords: orality — irony — memory — Jesús Moncada — Catalan literature.

\section{Abstract}

Jesús Moncada's narrative presents an oral substrate in the form of rumours, gossip, grudges or disputes that take place in the little village of Mequinensa, where everyone knows each other. Following the theories of Eric Havelock, Paul Zumthor, and Walter J. Ong, which identify in orality the source of any literary expression, we analyse the evolution of Maquinensan loud secrets and hidden truths into stories and how the skilful writer is able to turn simple anecdotes into great narrative plots. In this paper, several examples from short stories and novels are analysed, and the differences in the role of orality in each genre are described and examined. Furthermore, the role of casual conversation as an oral start-point of Moncada's stories is highlighted.

Fecha de recepción: 5.07.2018

Fecha de aceptación: 10.10.2018 